\title{
Identification and transcription profiling of NDUFS8 in Aedes taeniorhynchus (Diptera: Culicidae): developmental regulation and environmental response
}

\author{
This article was published in the following Dove Press journal: \\ Open Access Insect Physiology \\ 18 December 2014 \\ Number of times this article has been viewed
}

\author{
Liming Zhaol-3 \\ Daniel L Kline ${ }^{2}$ \\ James J Becnel ${ }^{2}$ \\ Jian Chen ${ }^{3}$ \\ Sandra A Allan ${ }^{2}$ \\ Gary G Clark ${ }^{2}$ \\ Kenneth J Linthicum ${ }^{2}$ \\ 'Florida Medical Entomology \\ Laboratory, University of Florida, \\ Vero Beach, FL, USA; ${ }^{2}$ Mosquito \\ and Fly Research Unit, Center for \\ Medical, Agricultural, and Veterinary \\ Entomology, Agriculture Research \\ Service, United States Department \\ of Agriculture, Gainesville, FL, USA; \\ ${ }^{3}$ Biological Control of Pests Research \\ Unit, National Biological Control \\ Laboratory, Agriculture Research \\ Service, United States Department of \\ Agriculture, Stoneville, MS, USA
}

Correspondence: Liming Zhao Florida Medical Entomology Laboratory, University of Florida, 200 9th Street South East, Vero Beach, FL 32962, USA

Tel +l 7727787200

Fax +I 7727787205

Emaillmzhao@ufl.edu

\begin{abstract}
The cDNA of a NADH dehydrogenase-ubiquinone Fe-S protein 8 subunit (NDUFS 8 ) gene from Aedes (Ochlerotatus) taeniorhynchus Wiedemann has been cloned and sequenced. The 824 bp full-length mRNA sequence of AetNDUFS 8 encodes an open reading region of $651 \mathrm{bp}$ (that is, 217 amino acids). To identify if AetNDUFS 8 is developmentally regulated, we employed a quantitative real-time polymerase chain reaction to examine AetNDUFS 8 gene expression levels in all developmental stages of Ae. taeniorhynchus. In egg, larval, and pupal stages, AetNDUFS 8 was expressed at relatively low levels. However, in the teneral adult stage, AetNDUFS8 was highly expressed. During the time course study in response to permethrin pesticide treatment, quantitative real-time polymerase chain reaction (PCR) also showed that mRNA transcription levels of AetNDUFS8 were regulated in female Ae. taeniorhynchus. A mitochondrially encoded NADH dehydrogenase subunit 5 AetNADH5 was highly expressed in different developmental stages of Ae. taeniorhynchus. This study suggests that AetNDUFS 8 and AetNADH5 play an essential role in the development of Ae. taeniorhynchus and will provide information useful for developing dsRNA pesticide for mosquito control.
\end{abstract}

Keywords: Aedes taeniorhynchus, AetNDUFS8, mRNA expression, development, permethrin

\section{Introduction}

NADH dehydrogenase, located in the inner mitochondrial membrane, is the first enzyme of the mitochondrial electron transport chain that catalyzes the transfer of electrons from NADH to coenzyme Q. ${ }^{1,2}$ Mitochondrial genes or mitochondrial related genes can be used as genetic markers to identify ecotypes in different populations of plants, ${ }^{3,4}$ and animals, including insects and mosquitoes. ${ }^{5-13}$ The critical role of NADH in the respiratory function of Complex I has been demonstrated by linking mutation in NADH subunits to certain hereditary disease, such as disease-causing mtDNA-encoded ND6 gene mutation. ${ }^{14}$

Aedes taeniorhynchus Wiedemann, a nuisance species, has attracted much attention recently., ${ }^{9,20}$ The aim of this study was to clone the NADH dehydrogenase-ubiquinone Iron-Sulfate ( $\mathrm{Fe}-\mathrm{S}$ ) protein 8 subunit (AetNDUFS8) gene and examine mRNA expression during development and in response to challenge by the permethrin pesticide. ${ }^{21}$ This information is important for understanding the role of NADH subunits in development and pesticide sensitivity in mosquitoes. Mitochondrially encoded NADH dehydrogenase subunit 5 (AetNADH5) has been 
used to identify the species on isolated oceanic islands. ${ }^{9}$ In the present study, AetNADH5 was examined during the development of Ae. taeniorhynchus. As part of our effort to develop new toxicants for applied mosquito control, understanding the role of mitochondrial genes from $A e$. taeniorhynchus in development and pesticide exposure may provide the information needed to identify and develop novel mosquito control strategies. ${ }^{22}$ Applying RNA interference (RNAi) technology to silence the mitochondrial proteins, AetNDUFS 8 and AetNADH5 genes may provide additional targets for developing dsRNA pesticides. ${ }^{22,23}$

\section{Materials and methods}

\section{Mosquito strain}

Ae. taeniorhynchus (Orlando, Florida strain, maintained since 1952) was reared in the insectary of the Mosquito and Fly Research Unit at the Center for Medical, Agricultural, and Veterinary Entomology, Agriculture Research Service, United States Department of Agriculture, Gainesville, FL. Temperature was maintained at $27^{\circ} \mathrm{C}$ and humidity, $80 \%$ $\mathrm{RH}$, respectively. Adult females without blood feed were maintained on $5 \%$ sucrose during all experiments. ${ }^{24}$

At each larval time point, samples were collected, each containing 100-150 larvae. Three samples were frozen in liquid nitrogen and then stored in the $-80^{\circ} \mathrm{C}$ freezer for RNA isolation. The remainder were fixed in $90 \%$ ethanol for measuring. The transverse diameter of head capsules was measured with a dissecting microscope (model Stemi SV8, Carl Zeiss, Thomwood, NY, USA) connected to a camera (model 11.2 Color Mosaic, Diagnostic Instruments, Sterling Heights, MI, USA).

Instar status was determined by the transverse diameter of the head capsules; $1 \mathrm{st}$ instar (mean, $0.319 \pm 0.034 \mathrm{~mm}), 2 \mathrm{nd}$ instar $(0.444 \pm 0.092 \mathrm{~mm}), 3 \mathrm{rd}$ instar $(0.731 \pm 0.155 \mathrm{~mm})$, and 4th instar $(1.057 \pm 0.159 \mathrm{~mm})$.

\section{RNA extraction}

All developmental stages (ie, eggs, larvae, pupae, and adults) of Ae. taeniorhynchus were collected at various time points within each stage. Fifty micrograms of three samples for the egg stage were collected. About 100-200 larvae for the larval stage were collected for the RNA extraction. About 15-20 pupae and adults were assembled for each sample. Three replicates of the experiment were conducted. To the samples $1 \mathrm{~mL}$ TRIzol reagent (Invitrogen, Carlsbad, CA, USA) was added and ground with tissue miser homogenizer. The total RNAs were then extracted according to the manufacturer's instructions. RNA samples were quantitated using the NanoDrop 2000, UV-Vis Spectrophotometer (Thermo Fisher Scientific Inc., Waltham, MA).

\section{GeneRacer cloning and gene sequencing of GeneRacer library}

GeneRacer cloning and gene sequencing of GeneRacer library were described in a previous publication. ${ }^{24}$ Selected plasmids were sequenced at the Sanger Sequencing Core Laboratory in the Interdisciplinary Center for Biotechnology Research, University of Florida (Gainesville, FL, USA). The DNA sequence was analyzed using SDSC Biology Workbench - San Diego Supercomputer Center (http:// workbench.sdsc.edu) and ExPASy (http://www.expasy. org/). The sequence was submitted to National Center for Biotechnology Information; GenBank Accession number: FJ458415.

\section{Permethrin experiments}

Five-day old adult female Ae. taeniorhynchus were topically treated to the scutum of thorax with permethrin/acetone at $2.5 \times 10^{-5} \mu \mathrm{g}$ (high dose, HD) and $1.25 \times 10^{-5} \mu \mathrm{g}$ (low dose, LD) per mosquito as previously described by Zhao et al. ${ }^{24,25}$ Ten mosquitoes per cup were used for all treatments. ${ }^{24}$ At each time course point, including 0 (blank control), 5, 15, 30, 60, and 180 minutes, and 6 hours and 24 hours, we collected 30 females after permethrin pesticide treatment. A control group was topically exposed to acetone only. ${ }^{25}$

\section{Quantitative real-time PCR amplification}

The method of cDNA synthesis is the same as described in the previous publication. ${ }^{24}$

The quantitative real-time PCR (qPCR) assay for AetNDUFS 8 and AetNADH5 mRNA expression in Ae. taeniorhynchus was performed as described in the previous publication. ${ }^{24,26}$ The PCR primers for ribosomal 40s gene are AET-40S-52F (5'-TGATGAGGCTTCTCCCTACG-3') and AET-40S-261R (5'-GGGATTGGGGTAACATCCTC-3'). The PCR primers for ribosomal 60s gene (GenBank accession number: FJ444827) are AET-60S-117F ( $5^{\prime}$ - T C T GCGTAAGCGGTGTAATG - 3') and AET-60S-336R (5'-GGGTGGTATGCCTTCGTAGA-3'). The PCR primers used were AET-NDUFS8-141F (5'-CAAGGACCCCAGTATGGAGA-3') and AETNDUFS8-415R (5'-GCTCTTCCGCTTCTATGGTG-3'). The PCR primers (GenBank accession number: FM992318) 
used were AET-NADH5-162F (5'-TCCAGAAATAATTTG TTTACCATTTT-3') and AET-NADH5-425R (5'-CCTCCA AAATATTCACTTCAACC-3'). The PCR thermal cycling parameters were also the same as previously published. ${ }^{24,27}$ Relative expression levels were determined as follows: first, Aet NADH transcript levels relative to a standard (ribosomal $40 \mathrm{~s} / 60 \mathrm{~s}$ ) were obtained by applying the formula $\Delta \mathrm{CT}=\mathrm{CT}$ (AetNADH) - CT (Aet-ribosomal 40s/60s). Second, an average $\Delta \mathrm{CT}$ value for each sample was determined. Third, relative expression levels were evaluated applying the modified equation $100 \times 2^{- \text {[average } \Delta \mathrm{CT}]} .^{28,29}$

\section{Sequence data analysis}

A multiple sequence alignment of AetNDUFS 8 and AetNADH5 as well as orthologs from other mosquitoes were performed with the MEGA 5.05 program (http://www.megasoftware.net). The Neighbor-joining method with the MEGA 5.05 program was used to construct the phylogenetic trees. ${ }^{30}$ The Neighbor-joining is a bottom-up clustering method for the creation of phenetic trees, based on the minimumevolution criterion. ${ }^{31}$

\section{Statistical analysis}

To determine significant difference, the SigmaPlot software was used for comparing two groups of data (SigmaPlot ${ }^{\circledR}$ 11.2, Inc., San Jose, CA, USA).

\section{Results}

\section{Identification of Ae. taeniorhynchus AetNDUFS8 gene}

The full-length cDNA sequence of AetNDUFS8 of Ae. taeniorhynchus was first deposited in GenBank by Zhao et $\mathrm{al}^{24}$ (accession number FJ458415). The AetNDUFS8 is 650 bp that codes for a protein of 217 amino acids with a molecular mass of $24.5 \mathrm{kDa}$ (GenBank accession number: ACL37997). A comparison AetNDUFS8 with NDUFS8 in Ae. aegypti (L.) (AY432654.1), Armigeres subalbatus (Coquillett) (AY440457.1), Anopheles gambiae Giles (BX042513.1), Culex quinquefasciatus Say (XM 001868794.1), and Drosophila species (AC010122.7; XM_002016993.1; XM_001980072.1;XM_002030974.1; XM_001359220.2; AY070919.1; NM_079980.2) revealed that they share 84\%, $83 \%, 82 \%, 81 \%$, and $77 \%-82 \%$ identity, respectively. Using the Neighbor-joining method with MEGA 5.05 program, a phylogenetic tree for AetNDUFS 8 nucleic acid sequences from other insect orthologs was constructed (Figure 1). The phylogenetic analysis demonstrated that AetNDUFS8 was closely related to Armigeres subalbatus Theobald and Aedes aegypti L. as well as Anopheles gambiae Giles.

AetNDUFS8 gene expression in all developmental stages of Ae. taeniorhynchus

To better understand how nuclear encoded mitochondrial genes are expressed during the development of $A e$. taeniorhynchus, we inspected AetNDUFS8 mRNA relative expression levels in all developmental stages (ie, eggs, larvae, pupae, and adults) employing qPCR (Figure 2, Tables S1-S3). In the egg stage, the relative mRNA expression level of AetNDUFS8 slightly increased from day 1 to day 3 during the time course study. The mRNA relative expression level of AetNDUFS 8 was slightly increased through the development of the 1st instar larva in the early ( 5 hours posthatch) to the late (53 hours posthatch) stage samples. AetNDUFS 8 expression was relatively high in the 2 nd instar larvae, the $3 \mathrm{rd}$ instar larvae, and early 4th instar larvae examined (from 69 hours posthatch to 125 hours posthatch). However, RNA relative expression level of AetNDUFS 8 was significantly higher in teneral male adults (mean, 33.158 \pm 1.573 ) when compared to teneral female adults (mean, 13.904 \pm 1.469 ). RNA expression of AetNDUFS 8 in the teneral male is significantly different from that in the teneral female (Table S2). mRNA expression levels of AetNDUFS8 in teneral male/female Ae. taeniorhynchus were significantly higher than those found in 5- and 10-day-old adults (Figure 2, Tables S1 and S2).

\section{AetNDUFS8 gene expression in response to permethrin}

To examine if the mRNA transcription of AetNDUFS8 in Ae. taeniorhynchus was affected by permethrin pesticide, 5-day old female mosquitoes were treated with two concentrations of permethrin (as described in the Materials and methods section) using acetone as a carrier. In female Ae. taeniorhynchus, the qPCR time courses of AetNDUFS8 mRNA expressed differently between HD and LD of the permethrin. In the 5-day old female Ae. taeniorhynchus, AetNDUFS8 expression decreased slightly for LD at 5 minutes post permethrin treatment and then increased for both doses at 15 minutes post permethrin treatment compared to treatment with acetone only as a control (Figure 3, Table S4, and S5). HD-treated and LD-treated permethrin/acetone for Ae. taeniorhynchus female adults showed a decrease in AetNDUFS 8 mRNA expression at 30 minutes postexposure, but a significant increase in AetNDUFS8 


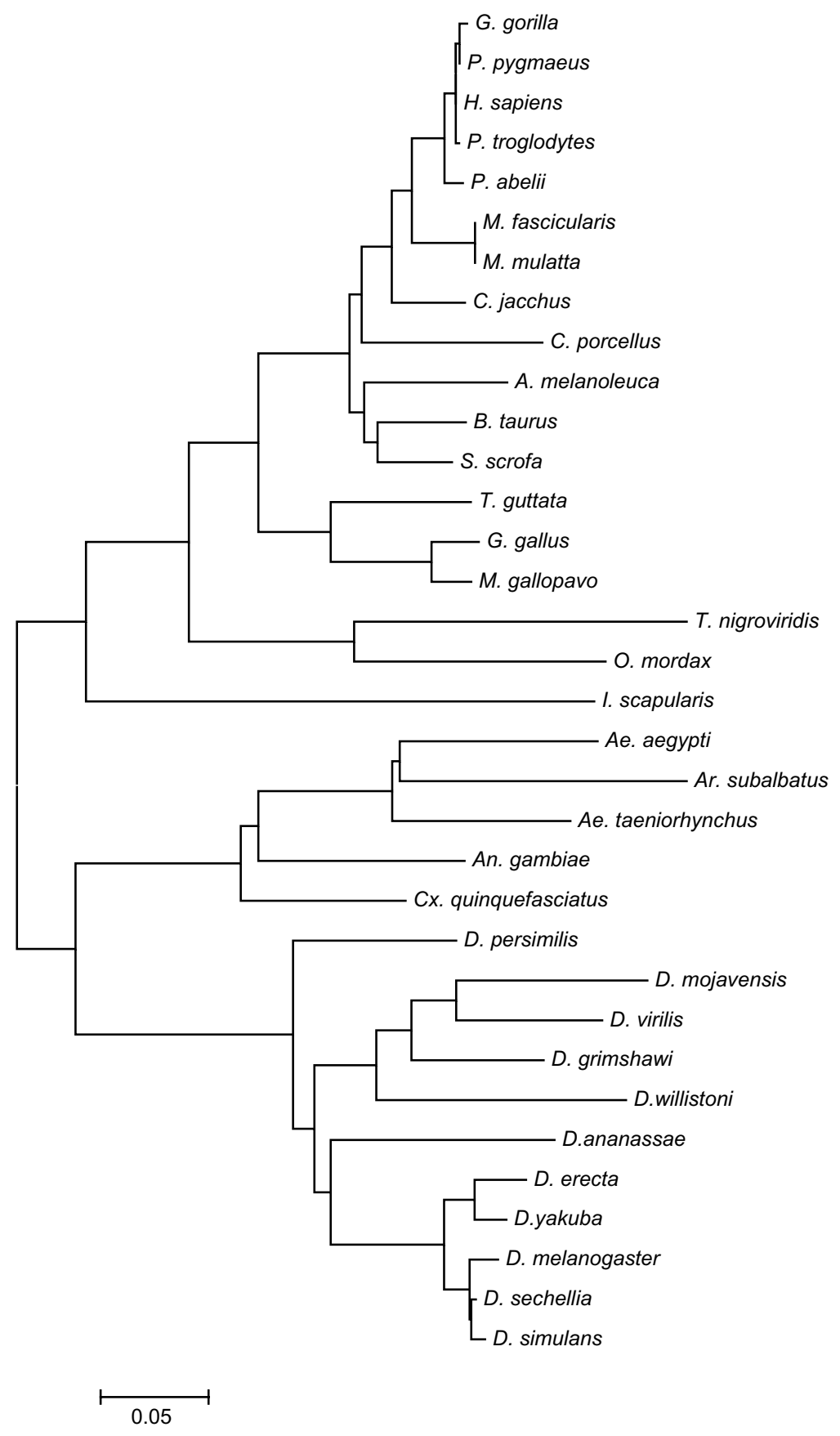

Figure I A phylogenetic tree for NDUFS8 orthologs.

Notes: The phylogenetic tree was constructed using the Neighbor-joining tree-making method for NDUFS8 nucleic acid sequences of NADH dehydrogenase-ubiquinone Fe-S protein 8 subunit from other orthologues using the MEGA 5.05 program. The scale bar indicates the number of changes inferred as having occurred along each branch. The accession number of nucleic acid sequences of NDUFS8 orthologues used in this analysis are FJ4584I5.I, AY432654.I, AY440457.I, XM_00I868794, XM32I378.5, XM_002I032227.I, XM_002030974, NM_0799980.3, XM_001980072.I, XM_002097653, XM_0019903I6, XM_002016993, XM_00I954946, XM_002056337.I, XM_001998624.I, XM_002074083.I, BX933502.2, XM_002755626.I, XM_002400792, NM_002496.3, NM_00III3I88I.I, XM_0034683I3, BT075206.I, CR7II559.2, XM_003I222435.I, XM_00292I294.I, DQ885653.I, NM_00I07I780.I, M587I7.I, DQ885652.I, XM_00II04I03.2, ABI25I84.I, XM_003206I48.I, and XM_002196863.I.

mRNA expression at 1 hour postexposure compared with the control treatment (Figure 3, Tables S4 and S5). Permethrin/ acetone HD-treated Ae. taeniorhynchus adults showed a decrease in AetNDUFS 8 mRNA expression at 3 hours postexposure, but permethrin/acetone LD-treated Ae. taeniorhynchus adults showed an increase in AetNDUFS8 RNA expression at 3 hours postexposure compared with treatment with acetone only. The qPCR data showed that AetNDUFS8 RNA expression levels after 6 hours treated with acetone only (control) were significantly increased in the 5-day female Ae. taeniorhynchus, 


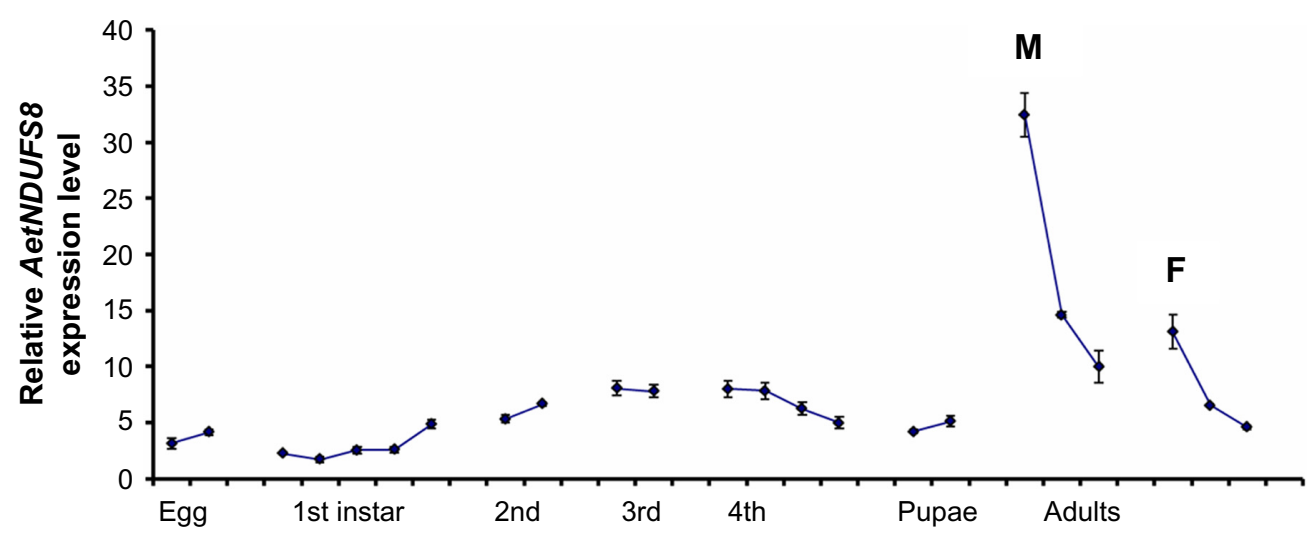

Figure 2 AetNDUFS8 mRNA expression levels in eggs, larvae, pupae, and adults quantified by qPCR, with SD for three replicates.

Notes: Ages of eggs, I d, and 3 d, respectively; First instar, 5, 21, 29, 44, and 53 h posthatch, respectively; second instar, 69, and 77 h posthatch respectively; third instar, 93 , and I0I h posthatch, respectively; fourth instar, II7, I25, I4I, and I49 h posthatch, respectively; pupae, I65, and I73 h posthatch, respectively; and adults, and I d old male, (M) designated male, (ie, $8 \mathrm{~d}$ posthatch); $5 \mathrm{~d}$ old male (ie, $13 \mathrm{~d}$ posthatch); and $10 \mathrm{~d}$ old male (ie, I $8 \mathrm{~d}$ posthatch); and I d old female, (F) designated female (ie, $8 \mathrm{~d}$ posthatch); $5 \mathrm{~d}$ old female (ie, $13 \mathrm{~d}$ posthatch); and $10 \mathrm{~d}$ old female (ie, $18 \mathrm{~d}$ posthatch).

Abbreviations: $d$, day; h, hours; mRNA, messenger RNA, qPCR, quantitative real-time polymerase chain reaction; SD, standard deviation.

and then decreased after 24 hours of being treated with acetone only (Figure 3, Table S4).

\section{AetNADH5 dehydrogenase gene expression in all developmental stages of Aedes taeniorhynchus}

To understand the developmental regulation of mitochondrial encoded NADH dehydrogenase transcript under different physiological conditions, qPCR was performed to examine Aet$N A D H 5$ relative transcription levels in eggs, larvae, pupae, and adults (Figure 4, Table S6). The relative transcription level of the AetNADH5 was a hundred to a thousand-fold higher than that of nuclear encoded AetNDUFS8. In the egg stage the relative
mRNA transcription level of AetNADH5 was highly expressed

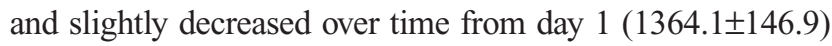
to day 3 (1278.1 \pm 35.84$)$. Compared with the egg stages, AetNADH5 mRNA expression was significantly reduced in the $1 \mathrm{st}$ instar larvae (116.28 \pm 5.16$)$ (Figure 4, Tables S3, S7, and S8). The RNA relative expression level of AetNADH5 was slightly increased through the development of the 1st instar larva in the early ( 21 hours posthatch) to the late (53 hours posthatch) stage samples. Compared with the 1st instar larvae, AetNADH5 expression was relatively high in the 2 nd instar larvae, the 3 rd instar larvae, and the 4th instar larvae examined (from 69 hours posthatch to 125 hours posthatch) (Figure 4, Tables S6 and S7). However, RNA relative expression level of AetNADH5

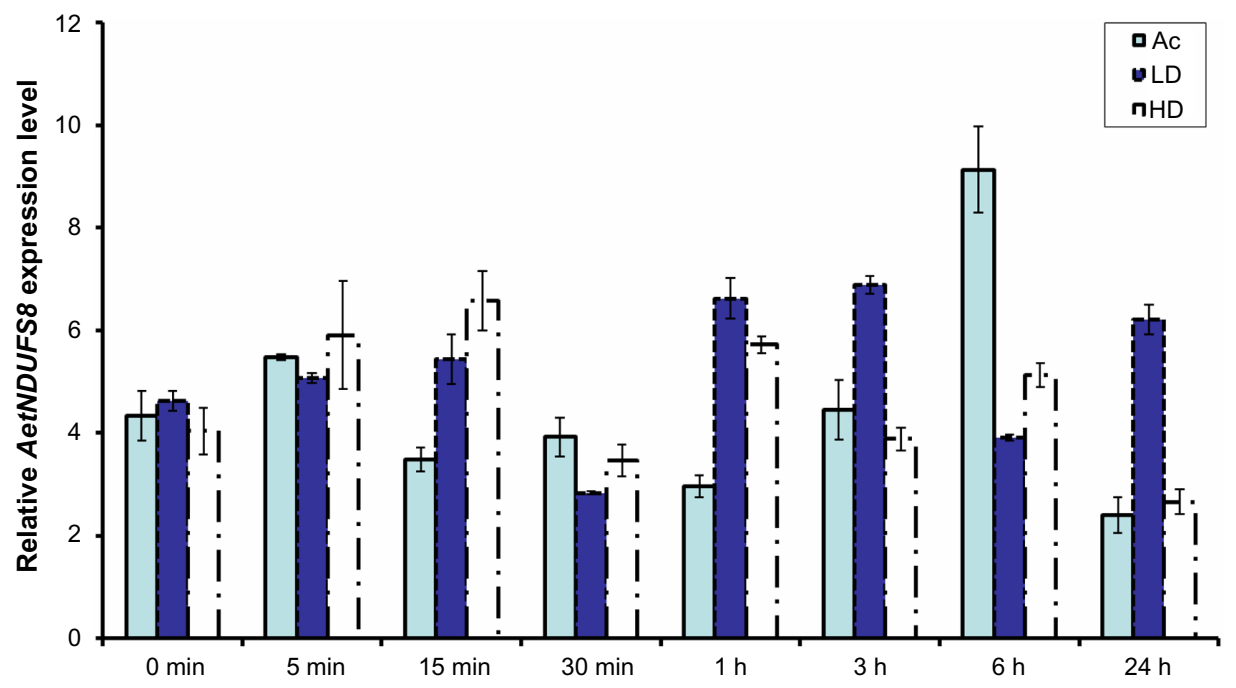

Figure 3 AetNDUFS 8 mRNA expression levels in $5 \mathrm{~d}$ old female treated topically with permethrin/acetone at $2.5 \times 10^{-5} \mu \mathrm{g}$ (high dose, $\mathrm{HD}$ ), and I.25 $\times 10^{-5} \mu \mathrm{g}$ (low dose, $\mathrm{LD}$ ) per mosquito, and acetone (Ac) quantified by qPCR, with standard deviation (SD) for three replicates. Please note X-axis is not to scale. Five-day-old adult postexposure to permethrin at $0,5,15,30,60,180$, and $360 \mathrm{~min}$, and $24 \mathrm{~h}$.

Abbreviations: $d$, day; h, hours; min, minutes; mRNA, messenger RNA; qPCR, quantitative real-time polymerase chain reaction. 


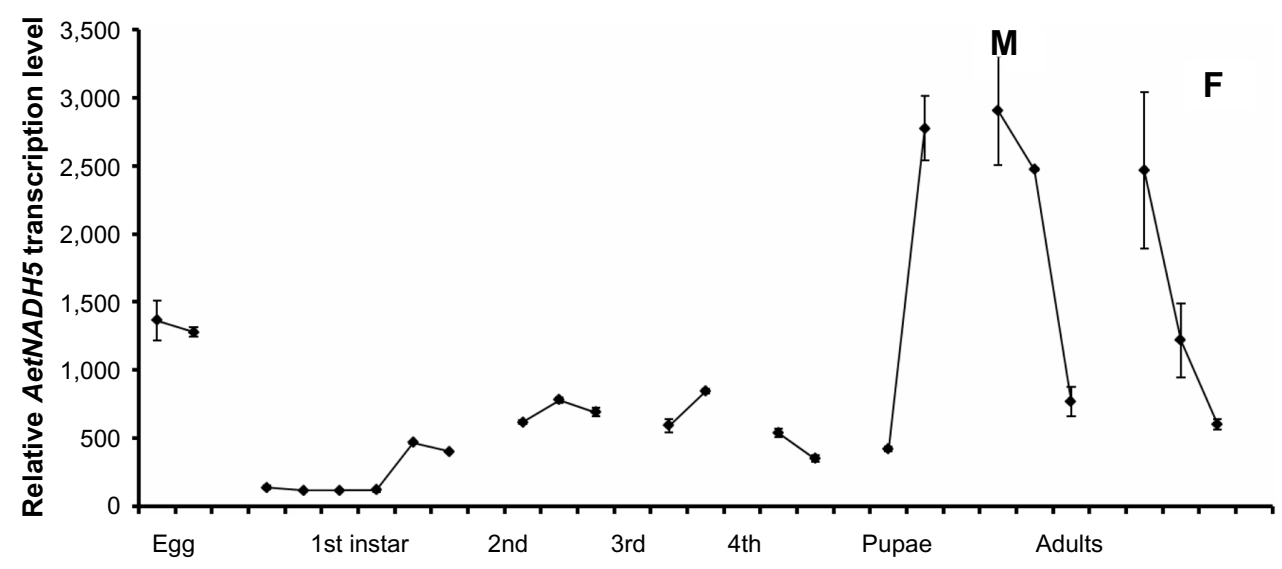

Figure 4 AetNADH5 mRNA expression levels in eggs, larvae, pupae, and adults quantified by qPCR, with SD for three replicates.

Notes: Ages of eggs, I d, and 3 d, respectively; First instar, 5, 21, 29, 44, and 53 h posthatch, respectively; second instar, 69, and 77 h posthatch respectively; third instar, 93 , and I0I h posthatch, respectively; fourth instar, II7, I25, I4I, and I49 h posthatch, respectively; pupae, I65, and I73 h posthatch, respectively; and adults, and I d old male, (M) designated male, (ie, $8 \mathrm{~d}$ posthatch); $5 \mathrm{~d}$ old male (ie, $13 \mathrm{~d}$ posthatch); and $10 \mathrm{~d}$ old male (ie, $18 \mathrm{~d}$ posthatch); and I d old female, (F) designated female (ie, $8 \mathrm{~d}$ posthatch); $5 \mathrm{~d}$ old female (ie, $13 \mathrm{~d}$ posthatch); and $10 \mathrm{~d}$ old female (ie, $18 \mathrm{~d}$ posthatch).

Abbreviations: $d$, day; h, hours; mRNA, messenger RNA; qPCR, quantitative real-time polymerase chain reaction; SD, standard deviation.

increased significantly between early pupae (422.33 \pm 19.69$)$ and late pupae $(2,775.9 \pm 1.469)$ mosquitoes. RNA relative expression level of AetNADH5 remained high between teneral male $(2,903.4 \pm 398.4)$ and female $(2,467.0 \pm 575.6)$ mosquitoes (Figure 4, Table S6). RNA expression of AetNADH5 in teneral adult Ae. taeniorhynchus was significantly higher than that found in 5- and 10-day-old adults (Figure 4, Tables S6, and S7).

\section{Discussion}

\section{AetNDUFS8 transcription during Ae. taeniorhynchus development}

The AetNDUFS8 mRNA transcriptions in Ae. taeniorhynchus eggs, larvae, pupae, and adults have been analyzed using qPCR. The AetNDUFS 8 mRNA is expressed at low levels in eggs and the early larval stages and is expressed in varying quantities during the late larval stages and pupae. AetNDUFS 8 mRNA transcription varied in females and males of different ages. There were significant differences in the transcription of AetNDUFS8 between teneral and 10-day-old Ae. taeniorhynchus females and males (Figure 2). In males, AetNDUFS8 mRNA expression is higher than in females for all ages examined. In addition, AetNDUFS 8 expression was significantly different between teneral males and females (Figure 2), which may suggest that AetNDUFS8 plays an important and different role depending on adult $A e$. taeniorhynchus sex and age. AetNDUFS8 gene expression in mature mosquitoes is crucial for mitochondrial functions and may also be related to mosquito aging. Furthermore, the relatively lower levels of AetNDUFS8 transcription in older or senescent females and males suggests that mitochondrial dysfunction may also play a role in the attenuation of gene expression, which is similar to the cytochrome $C$ gene expression in Ae. aegypti. ${ }^{32}$

\section{Effect of permethrin on AetNDUFS8 mRNA expression}

Over the past decade, molecular studies of insecticide resistance have advanced rapidly. Many genes involved in target site and metabolic resistance mechanisms have been identified. The transcriptional regulation of gene expression is a primary approach by which insects adapt to a changing environment. ${ }^{32}$ The evolution of insecticide resistance acts by selection of these mechanisms, typically requiring the interaction of multiple genes. ${ }^{32}$ It is also reported that pesticides affected the interaction of multiple genes in mosquitoes. ${ }^{32,33}$ In the other study, the expression of $\sim 1 / 4$ of the detoxification genes in An. gambiae was found to be developmentally regulated. ${ }^{34}$ One of the best-known organic pesticides is Rotenone, an inhibitor of Complex I, which is found in several genera of tropical leguminosae plants. ${ }^{35}$ Several hydrophobic and amphipathic compounds including some detergents inhibit the ubiquinone reductase reaction of respiratory chain Complex I. ${ }^{36}$

AetNDUFS8 mRNA expression levels of 5-day old adults of Ae. taeniorhynchus were significantly upregulated at 15 minutes after permethrin treatments (both HD and LD). During the time course study, AetNDUFS 8 mRNA expression level of 5-day old female adults of Ae. taeniorhynchus showed unpredictable fluctuation between HD and LD permethrin treatments compared with the control. This indicated that AetNDUFS8 transcript levels in adult Ae. taeniorhynchus might have differences in response to the different concentration of permethrin treatment, which might 
reveal the pesticide mechanism in the mosquito related role of the NADH in the respiratory function of Complex I. Furthermore, understanding of the pesticide mechanism in the mosquito may help to find new inhibitors of Complex I, which could be used as new pesticides. ${ }^{21}$

\section{Mitochondrially encoded AetNADH5 transcription during Ae. taeniorhynchus development}

In the current study, we also demonstrated the expression of AetNADH5 in different developmental stages of Ae. taeniorhynchus by qPCR. Our results revealed that AetNADH5 was expressed throughout the developmental stages of Ae. taeniorhynchus. However, the expression level of AetNADH5 in embryonic stage was significantly higher than that in the larval stages (Figure 3 ). This observation is of importance in that it suggests that AetNADH5 might play a functional role in embryonic development in $A e$. taeniorhynchus. Our results also revealed that AetNADH5 expression levels in late pupal and early adult stages were significantly higher than in the larval stage. Furthermore, at different times within each developmental stage, the expression levels of AetNADH5 were different, suggesting that AetNADH5 plays a critical role throughout the physiological process of the development of Ae. taeniorhynchus. Meanwhile, the relative low levels of AetNADH transcription in older or senescent males and females suggest that mitochondrial dysfunction may also play a role in the attenuation of gene expression, which is similar to the cytochrome $c$ and cytochrome $b$ gene expression in the Ae. aegypti. ${ }^{26,27}$

The crucial role of NADH in the respiratory function of Complex I has been demonstrated by linking mutation in subunits to certain diseases. ${ }^{14}$ In humans, mutations in the subunits of Complex I can cause mitochondrial diseases, including Leigh syndrome known as Subacute Necrotizing Encephalomyelopathy. ${ }^{37-40}$ Mitochondrial dysfunction has been associated with Parkinson's disease, particularly widely demonstrated in Complex I impairment and subsequent oxidative stress. ${ }^{41-45}$ There are also many mitochondrial dysfunction mutations in insects, such as Drosophila. $^{46-50}$

The mitochondrial gene expression data can be used in RNAi studies to investigate the functional role of mitochondrial genes in mosquito development. The mitochondrial gene NADH can also provide information to identify ecotypes of mosquitoes from different geographical locations in the United States and other countries. ${ }^{9}$
In conclusion, the expressions of AetNDUFS8 and AetNADH5 in the life cycle of Ae. taeniorhynchus were regulated developmentally and environmentally. The mRNA expressions of AetNDUFS8 and AetNADH5 have, for the first time, been examined in detail for all developmental stages of Ae. taeniorhynchus. This study suggests that AetNDUFS 8 and AetNADH5 play an important role in the development of Ae. taeniorhynchus and will provide information useful for designing dsRNA pesticide for mosquito control.

\section{Acknowledgments}

We thank Drs SM Valles (USDA-ARS) and L Zhang (Delta Research and Extension Center, Mississippi State University) for critical reviews of the manuscript. We also thank Neil Sanscrainte and Kelly Anderson (USDA-ARS) for their helpful support. The current study was supported by a grant from the Deployed War-Fighter Protection Research Program funded by the US Department of Defense through the Armed Forces Pest Management Board.

\section{Disclosure}

The authors report no conflicts of interest in this work.

\section{References}

1. Hochstein LI, Dalton BP. Studies of a halophilic NADH dehydrogenase. I. Purification and properties of the enzyme. Biochim Biophys Acta. 1973;302(2):216-228.

2. Adachi K, Okuyama T. Study on the reduced pyridine nucleotide dehydrogenase of bovine erythrocytes. I. Crystallization and properties of the reduced pyridine nucleotide dehydrogenase of bovine erythrocytes. Biochi Biophys Acta. 1972;268(3):629-637.

3. Kai K, Shimizu B, Mizutani M, Watanabe K, Sakata K. Accumulation of coumarins in Arabidopsis thaliana. Phytochemistry. 2006;67(4): 379-386.

4. Duan H, Huang MY, Palacio K, Schuler MA. Variations in CYP74B2 (hydroperoxide lyase) gene expression differentially affect hexenal signaling in the Columbia and Landsberg erecta ecotypes of Arabidopsis. Plant Physiol. 2005;139(3):1529-1544

5. De Merida AM, Palmieri M, Yurrita M, Molina A, Molina E, Black WC 4th. Mitochondrial DNA variation among Anopheles albimanus populations. Am J Trop Med Hyg. 1999;61(2):230-239.

6. Shaikevich EV, Vinogradova EB, Platonov AE, Karan LS, Zakharov IA. [Polymorphism of mitochondrial DNA and infection with symbiotic cytoplasmic bacterium Wolbachia pipientis in mosquitoes of the Culex pipiens complex from Russia]. Genetika. 2005;41(3):320-325. Russian.

7. Coates BS, Sumerford DV, Hellmich RL. Geographic and voltinism differentiation among North American Ostrinia nubilalis (European corn borer) mitochondrial cytochrome c oxidase haplotypes. $J$ Insect Sci. 2004;4:35.

8. Shaikevich EV, Vinogradova EB. [Molecular genetic methods for the identification of the urban mosquito Culex pipiens pipiens F. molestus (Diptera, Culicidae)]. Parazitologiia. 2004;38(5):406-412. Russian.

9. Bataille A, Cunningham AA, Cedeno V, et al. Natural colonization and adaptation of a mosquito species in Galapagos and its implications for disease threats to endemic wildlife. Proc Natl Acad Sci U S A 2009;106(25):10230-10235. 
10. Borghuis A, van Groenendael J, Madsen O, Ouborg J. Phylogenetic analyses of the leaf beetle genus Galerucella: evidence for host switching at speciation? Mol Phylogenet Evol. 2009;53(2):361-367.

11. Rasgon JL, Cornel AJ, Scott TW. Evolutionary history of a mosquito endosymbiont revealed through mitochondrial hitchhiking. Proc Biol Sci. 2006;273(1594):1603-1611.

12. Barr NB, McPheron BA. Molecular phylogenetics of the genus Ceratitis (Diptera: Tephritidae). Mol Phylogenet Evol. 2006;38(1): 216-230.

13. Bourke B, Foster P, Bergo E, Calado D, Sallum M. Phylogenetic relationships among species of Anopheles (Nyssorhynchus) (Diptera, Culicidae) based on nuclear and mitochondrial gene sequences. Acta Trop. 2010;114(2):88-96.

14. Bai Y, Attardi G. The mtDNA-encoded ND6 subunit of mitochondrial NADH dehydrogenase is essential for the assembly of the membrane arm and the respiratory function of the enzyme. EMBO J. 1998;17(16):4848-4858.

15. Dame DA, Wichterman GJ, Hornby JA. Mosquito (Aedes taeniorhynchus) resistance to methoprene in an isolated habitat. J Am Mosq Control Assoc. 1998;14(2):200-203.

16. Smith DR, Adams AP, Kenney JL, Wang E, Weaver SC. Venezuelan equine encephalitis virus in the mosquito vector Aedes taeniorhynchus: infection initiated by a small number of susceptible epithelial cells and a population bottleneck. Virology. 2008;372(1):176-186.

17. Arrigo NC, Watts DM, Frolov I, Weaver SC. Experimental infection of Aedes sollicitans and Aedes taeniorhynchus with two chimeric Sindbis/ Eastern equine encephalitis virus vaccine candidates. Am J Trop Med Hyg. 2008;78(1):93-97.

18. Bello F, Becerra V. Genetic variability and heterogeneity of Venezuelan equine encephalitis virus vector Ochlerotatus taeniorhynchus (Diptera: Culicidae) populations of the Colombian Atlantic coast, based on microsatellite loci. Genet Mol Res. 2009;8(3):1179-1190.

19. Manrique-Saide P, Bolio-González M, Sauri-Arceo C, Dzib-Florez S, Zapata-Peniche A. Ochlerotatus taeniorhynchus: a probable vector of Dirofilaria immitis in coastal areas of Yucatan, Mexico. J Med Entomol. 2008;45(1):169-171.

20. Xue R, Ali A, Kline D, Barnard D. Field evaluation of boric acid- and fipronil-based bait stations against adult mosquitoes. J Am Mosq Control Assoc. 2008;24(3):415-418.

21. Gassner B, Wüthrich A, Scholtysik G, Solioz M. The pyrethroids permethrin and cyhalothrin are potent inhibitors of the mitochondrial complex I. J Pharmacol Exp Ther. 1997;281(2):855-860.

22. Singh AD, Wong S, Ryan CP, Whyard S. Oral delivery of doublestranded RNA in larvae of the yellow fever mosquito, Aedes aegypti: implications for pest mosquito control. J Insect Sci. 2013;13:69.

23. Pridgeon JW, Zhao L, Becnel JJ, Strickman DA, Clark GG, Linthicum KJ. Topically applied AaeIAP1 double-stranded RNA kills female adults of Aedes aegypti. J Med Entomol. 2008;45(3):414-420.

24. Zhao L, Chen J, Becnel JJ, Kline DL, Clark GG, Linthicum KJ. Identification and transcription profiling of trypsin in Aedes taeniorhynchus (Diptera: Culicidae): developmental regulation, blood feeding, and permethrin exposure. J Med Entomol. 2011;48(3):546-553.

25. Pridgeon JW, Meepagala KM, Becnel JJ, Clark GG, Pereira RM, Linthicum KJ. Structure-activity relationships of 33 piperidines as toxicants against female adults of Aedes aegypti (Diptera: Culicidae). J Med Entomol. 2007;44(2):263-269.

26. Zhao L, Pridgeon J, Becnel J, Clark G, Linthicum K. Mitochondrial gene cytochrome $\mathrm{b}$ developmental and environmental expression in Aedes aegypti (Diptera: Culicidae). J Med Entomol. 2009;46(6): 1361-1369.

27. Zhao L, Pridgeon J, Becnel J, Clark G, Linthicum K. Cytochrome c gene and protein expression: developmental regulation, environmental response, and pesticide sensitivity in Aedes aegypti. J Med Entomol. 2008;45(3):401-408.

28. Zhao L, Pridgeon JW, Becnel JJ, Clark GG, Linthicum KJ. Cytochrome c gene and protein expression: developmental regulation, environmental response, and pesticide sensitivity in Aedes aegypti. J Med Entomol. 2008;45(3):401-408.
29. Portereiko M, Lloyd A, Steffen J, Punwani J, Otsuga D, Drews G. AGL80 is required for central cell and endosperm development in Arabidopsis. Plant Cell. 2006;18(8):1862-1872.

30. Tamura K, Dudley J, Nei M, Kumar S. MEGA4: Molecular Evolutionary Genetics Analysis (MEGA) software version 4.0. Mol Biol Evol. 2007;24(8):1596-1599.

31. Saitou N, Nei M. The Neighbor-joining method: a new method for reconstructing phylogenetic trees. Mol Biol Evol. 1987;4(4):406-425.

32. Liu N, Liu H, Zhu F, Zhang L. Differential expression of genes in pyrethroid resistant and susceptible mosquitoes, Culex quinquefasciatus (S.). Gene. 2007;394(1-2):61-68

33. Pridgeon J, Becnel J, Clark G, Linthicum K. Permethrin induces overexpression of multiple genes in Aedes aegypti. J Med Entomol. 2009;46(3):580-587.

34. Strode C, Steen K, Ortelli F, Ranson H. Differential expression of the detoxification genes in the different life stages of the malaria vector Anopheles gambiae. Insect Mol Biol. 2006;15(4):523-530.

35. Moretti C, Grenand P. [The "nivrées", or ichthyotoxic plants of French Guyana]. J Ethnopharmacol. 1982;6(2):139-160. French

36. Fendel U, Tocilescu M, Kerscher S, Brandt U. Exploring the inhibitor binding pocket of respiratory complex I. Biochim Biophys Acta. 2008;1777(7-8):660-665.

37. Sarzi E, Brown M, Lebon S, et al. A novel recurrent mitochondrial DNA mutation in ND3 gene is associated with isolated complex I deficiency causing Leigh syndrome and dystonia. Am J Med Genet A. 2007;143(1):33-41.

38. Pagliarini D, Calvo S, Chang B, et al. A mitochondrial protein compendium elucidates complex I disease biology. Cell. 2008;134(1): $112-123$.

39. Hoefs S, Dieteren C, Distelmaier F, et al. NDUFA2 complex I mutation leads to Leigh disease. Am J Hum Genet. 2008;82(6):1306-1315.

40. Lim B, Park J, Hwang H, et al. Mutations in ND subunits of complex I are an important genetic cause of childhood mitochondrial encephalopathies. J Child Neurol. 2009;24(7):828-832.

41. Vila M, Ramonet D, Perier C. Mitochondrial alterations in Parkinson's disease: new clues. J Neurochem. 2008;107(2):317-328.

42. Papa S, Petruzzella V, Scacco S, et al. Pathogenetic mechanisms in hereditary dysfunctions of complex I of the respiratory chain in neurological diseases. Biochim Biophys Acta. 2009;1787(5):502-517.

43. Shinde S, Pasupathy K. Respiratory-chain enzyme activities in isolated mitochondria of lymphocytes from patients with Parkinson's disease: preliminary study. Neurol India. 2006;54(4):390-393.

44. Varghese M, Pandey M, Samanta A, Gangopadhyay PK, Mohanakumar KP. Reduced NADH coenzyme Q dehydrogenase activity in platelets of Parkinson's disease, but not Parkinson plus patients, from an Indian population. J Neurol Sci. 2009;279(1-2):39-42.

45. Cavelier L, Erikson I, Tammi M, et al. MtDNA mutations in maternally inherited diabetes: presence of the 3397 ND1 mutation previously associated with Alzheimer's and Parkinson's disease. Hereditas. 2001;135(1):65-70.

46. Park J, Kim Y, Chung J. Mitochondrial dysfunction and Parkinson's disease genes: insights from Drosophila. Dis Model Mech. 2009;2(7-8): 336-340.

47. Liu W, Gnanasambandam R, Benjamin J, Kaur G, Getman P, Siegel A, et al. Mutations in cytochrome c oxidase subunit VIa cause neurodegeneration and motor dysfunction in Drosophila. Genetics. 2007;176(2):937-946.

48. Rikhy R, Kamat S, Ramagiri S, Sriram V, Krishnan K. Mutations in dynamin-related protein result in gross changes in mitochondrial morphology and affect synaptic vesicle recycling at the Drosophila neuromuscular junction. Genes Brain Behav. 2007;6(1):42-53.

49. Chang K, Min K. Drosophila melanogaster homolog of Down syndrome critical region 1 is critical for mitochondrial function. Nat Neurosci. 2005;8(11):1577-1585.

50. Shahrestani P, Leung H, Le P, et al. Heterozygous mutation of Drosophila Opal causes the development of multiple organ abnormalities in an agedependent and organ-specific manner. PLoS One. 2009;4(8):e6867. 


\section{Supplementary materials}

Table SI Expression of AetNDUFS8 in different developmental stages of Aedes taeniorhynchus

\begin{tabular}{|c|c|c|c|c|c|c|c|c|}
\hline \multirow[t]{2}{*}{ Sample stage } & \multirow{2}{*}{$\begin{array}{l}\text { Sample } \\
\text { name }\end{array}$} & \multirow{2}{*}{$\begin{array}{l}\text { Sample } \\
\text { time }\end{array}$} & \multicolumn{2}{|c|}{ Mean cycle threshold $(C t) \pm S D$} & \multicolumn{4}{|c|}{ Relative AetNDUFS8 expression level } \\
\hline & & & rR40s & AetNDUFS8 & $\Delta \mathrm{Ct}-\mathrm{I}$ & $\Delta C t-2$ & $\Delta \mathrm{Ct}-3$ & $100 \times 2^{-\Delta C t} \pm S D$ \\
\hline \multirow[t]{2}{*}{ Eggs } & Egg I & Id & $|4.089 \pm 0.04|$ & $19.156 \pm 0.045$ & 5.064 & 5.069 & 5.067 & $2.984 \pm 0.07 \mid$ \\
\hline & Egg 2 & $3 d$ & $14.840 \pm 0.013$ & $19.509 \pm 0.039$ & 4.669 & 4.649 & 4.688 & $3.93 I \pm 0.074$ \\
\hline \multirow[t]{5}{*}{ Ist instar larvae } & Larvae I & $5 \mathrm{~h}^{\mathrm{a}}$ & I I.588 \pm 0.209 & $17.044 \pm 0.127$ & 5.398 & 5.515 & 5.462 & $2.279 \pm 0.132$ \\
\hline & Larvae 2 & $21 \mathrm{~h}^{\mathrm{a}}$ & $10.852 \pm 0.101$ & $16.585 \pm 0.143$ & 5.704 & 5.763 & 5.733 & $1.880 \pm 0.054$ \\
\hline & Larvae 3 & $29 \mathrm{~h}^{\mathrm{a}}$ & $12.815 \pm 0.182$ & $|8.12| \pm 0.038$ & 5.461 & 5.149 & 5.305 & $2.544 \pm 0.386$ \\
\hline & Larvae 4 & $44 \mathrm{~h}^{\mathrm{a}}$ & $12.815 \pm 0.182$ & $17.532 \pm 0.057$ & 5.093 & 5.242 & 5.167 & $2.787 \pm 0.203$ \\
\hline & Larvae 5 & $53 \mathrm{~h}^{\mathrm{a}}$ & $13.060 \pm 0.115$ & $17.326 \pm 0.023$ & 4.331 & 4.199 & 4.265 & $5.205 \pm 0.334$ \\
\hline \multirow[t]{2}{*}{ 2nd instar larvae } & Larvae 6 & $69 \mathrm{~h}^{\mathrm{a}}$ & $12.933 \pm 0.012$ & $|7.21| \pm 0.1||$ & 4.192 & 4.365 & 4.278 & $5.162 \pm 0.439$ \\
\hline & Larvae 7 & $77 h^{a}$ & $13.100 \pm 0.055$ & $17.310 \pm 0.036$ & 3.919 & 3.939 & 3.929 & $6.564 \pm 0.062$ \\
\hline \multirow[t]{2}{*}{ 3rd instar larvae } & Larvae 8 & $93 \mathrm{~h}^{\mathrm{a}}$ & $12.339 \pm 0.034$ & $16.054 \pm 0.005$ & 3.742 & 3.726 & 3.688 & $7.617 \pm 0.202$ \\
\hline & Larvae 9 & $101 h^{a}$ & $|2.427 \pm 0.02|$ & $16.148 \pm 0.013$ & 3.725 & 3.715 & 3.720 & $7.586 \pm 0.039$ \\
\hline \multirow[t]{4}{*}{ 4th instar larvae } & Larvae 10 & $117 h^{a}$ & $12.386 \pm 0.034$ & $|6.13| \pm 0.033$ & 3.747 & 3.742 & 3.744 & $7.459 \pm 0.015$ \\
\hline & Larvae II & $125 h^{a}$ & $13.228 \pm 0.060$ & $17.005 \pm 0.077$ & 3.789 & 3.765 & 3.777 & $7.295 \pm 0.086$ \\
\hline & Larvae 12 & $|4| h^{a}$ & $13.845 \pm 0.064$ & $17.803 \pm 0.129$ & 3.821 & 4.095 & 3.958 & $6.464 \pm 0.864$ \\
\hline & Larvae 13 & $149 \mathrm{~h}^{\mathrm{a}}$ & $14.210 \pm 0.007$ & $15.316 \pm 0.044$ & 4.211 & 4.216 & 4.214 & $5.390 \pm 0.013$ \\
\hline \multirow[t]{2}{*}{ Pupae } & $\mathrm{PI}$ & $165 h^{a}$ & $|4.19| \pm 0.020$ & $|8.7| 7 \pm 0.01 \mid$ & 4.518 & 4.534 & 4.526 & $4.34 I \pm 0.034$ \\
\hline & P3 & $173 h^{a}$ & $15.216 \pm 0.026$ & $19.568 \pm 0.043$ & 4.401 & 4.303 & 4.352 & $4.901 \pm 0.235$ \\
\hline \multirow[t]{6}{*}{ Adults } & $\mathrm{Al}(\mathrm{M})^{\mathrm{b}}$ & Id & $|5.887 \pm 0.02|$ & $17.480 \pm 0.048$ & 1.545 & 1.642 & 1.593 & $33.158 \pm 1.573$ \\
\hline & $\mathrm{A} 2(\mathrm{M})^{\mathrm{b}}$ & $5 d$ & $|8.64| \pm 0.076$ & $21.423 \pm 0.034$ & 2.811 & 2.751 & $2.78 I$ & $14.549 \pm 0.426$ \\
\hline & $\mathrm{A} 3(\mathrm{M})^{\mathrm{b}}$ & $10 \mathrm{~d}$ & $|7.96| \pm 0.055$ & $21.257 \pm 0.190$ & 3.200 & 3.391 & 3.296 & $10.204 \pm 0.954$ \\
\hline & $\mathrm{Al}(\mathrm{F})^{\mathrm{c}}$ & Id & $15.787 \pm 0.073$ & $18.637 \pm 0.226$ & 2.959 & 2.742 & 2.850 & $13.904 \pm 1.469$ \\
\hline & $A 2(F)^{c}$ & $5 d$ & $15.273 \pm 0.026$ & $19.226 \pm 0.006$ & 3.976 & 3.931 & 3.953 & $6.457 I \pm 0.143$ \\
\hline & A3 $(F)^{c}$ & $10 \mathrm{~d}$ & $15.987 \pm 0.039$ & $20.389 \pm 0.046$ & 4.397 & 4.407 & 4.402 & $4.729 \pm 0.023$ \\
\hline
\end{tabular}

Notes: a Hours post hatch; 'bmales; ' females.

Abbreviations: d, day; F, female; M, male; SD, standard deviation.

Table S2 Paired $t$-test data for comparison of relative AetNDUFS8 gene transcription between female $(F)$ and male $(M)$, as well as different ages between the same sex (either female or male) in Aedes taeniorhynchus

\begin{tabular}{lllll}
\hline Sexes and ages & $\mathbf{N}$ & $\mathbf{d f}$ & $\boldsymbol{t}$-value & $\boldsymbol{P}$-value \\
\hline FI-d and MI-d & 3 & 2 & $-15.84 I$ & $0.004^{*}$ \\
F5-d and M5-d & 3 & 2 & -70.216 & $<0.00 I^{*}$ \\
FI0-d and MI0-d & 3 & 2 & -14.410 & $0.005^{*}$ \\
FI-d and F5-d & 3 & 2 & 14.583 & $0.005^{*}$ \\
FI-d and FI0-d & 3 & 2 & $15.85 I$ & $0.004^{*}$ \\
MI-d and M5-d & 3 & 2 & 22.810 & $0.002^{*}$ \\
MI-d and MI0-d & 3 & 2 & 90.879 & $<0.00$ F $^{*}$
\end{tabular}

Note: *Statistical significance $(P<0.05)$.

Abbreviations: $d$, day; $d f$, degrees of freedom.
Table S3 Paired $t$-test data for comparison of relative AetNDUFS8 gene transcription between eggs, larvae, pupae, and adults in Aedes taeniorhynchus

\begin{tabular}{|c|c|c|c|c|}
\hline Stage and ages & $\mathbf{N}$ & $d f$ & $t$-value & $P$-value \\
\hline Egg I and egg 3 & 3 & 2 & -34.939 & $<0.00 I^{*}$ \\
\hline Egg 3 and larvae I & 3 & 2 & -71.951 & $<0.001^{*}$ \\
\hline Larvae I and larvae 2 & 3 & 2 & $|2.86|$ & $0.006^{*}$ \\
\hline Larvae 2 and larvae 3 & 3 & 2 & 3.691 & 0.066 \\
\hline Larvae 3 and larvae 4 & 3 & 2 & -1.012 & 0.418 \\
\hline Larvae 4 and larvae 5 & 3 & 2 & 11.008 & $0.008^{*}$ \\
\hline Larvae 5 and larvae 6 & 3 & 2 & 0.136 & 0.904 \\
\hline Larvae 6 and larvae 7 & 3 & 2 & 9.026 & $0.012^{*}$ \\
\hline Larvae 7 and larvae 8 & 3 & 2 & -9.897 & $0.010 *$ \\
\hline Larvae 8 and larvae 9 & 3 & 2 & -0.462 & 0.689 \\
\hline Larvae 9 and larvae 10 & 3 & 2 & 12.522 & $0.006 *$ \\
\hline Larvae I0 and larvae II & 3 & 2 & -5.675 & $0.030 *$ \\
\hline Larvae II and larvae 12 & 3 & 2 & 2.139 & 0.166 \\
\hline Larvae 12 and larvae 13 & 3 & 2 & -3.088 & 0.091 \\
\hline Larvae I3 and pupae I & 3 & 2 & 120.587 & $<0.00 I^{*}$ \\
\hline Pupae I and pupae 2 & 3 & 2 & 5.095 & $0.036 *$ \\
\hline Pupae 2 and MI-d & 3 & 2 & -17.856 & $0.003 *$ \\
\hline Pupae 2 and FI-d & 3 & 2 & -38.296 & $<0.00 I^{*}$ \\
\hline
\end{tabular}

Note: *Statistical significance $(P<0.05)$.

Abbreviations: $d$, day; $d f$, degrees of freedom, $F$, female; $M$, male. 
Table S4 Expression of AetNDUFS8 under permethrin stress conditions in Aedes taeniorhynchus

\begin{tabular}{|c|c|c|c|c|c|c|}
\hline \multirow[t]{2}{*}{ Time point } & \multicolumn{2}{|c|}{ Mean cycle threshold $(C t) \pm S D$} & \multicolumn{4}{|c|}{ Relative AetNDUFS8 expression level } \\
\hline & rR40s & AetNDUFS8 & $\Delta \mathrm{Ct}-\mathrm{I}$ & $\Delta \mathrm{Ct}-2$ & $\Delta \mathrm{Ct}-3$ & $100 \times 2^{-\Delta C t} \pm S D$ \\
\hline Ac-0 $\min ^{\mathrm{a}}$ & $13.287 \pm 0.022$ & $17.822 \pm 0.063$ & 4.374 & 4.697 & 4.536 & $4.3117 \pm 0.685$ \\
\hline Ac-5 min & $13.687 \pm 0.064$ & $17.879 \pm 0.040$ & 4.175 & 4.209 & 4.191 & $5.47|7 \pm 0.09|$ \\
\hline Ac- 15 min & $12.679 \pm 0.153$ & $17.526 \pm 0.289$ & 4.751 & 4.943 & 4.847 & $3.4826 \pm 0.326$ \\
\hline Ac-30 min & $12.647 \pm 0.077$ & $17.325 \pm 0.120$ & 4.538 & 4.817 & 4.678 & $3.9255 \pm 0.535$ \\
\hline Ac-I h & $12.217 \pm 0.012$ & $17.296 \pm 0.136$ & 4.973 & 5.183 & 5.078 & $2.9678 \pm 0.305$ \\
\hline Ac-3 h & $12.693 \pm 0.290$ & $17.191 \pm 0.025$ & 4.686 & 4.311 & 4.498 & $4.4627 \pm 0.816$ \\
\hline Ac-6 h & $|3.229 \pm 0.26|$ & $16.688 \pm 0.072$ & 3.591 & 3.325 & 3.458 & $9.1385 \pm 1.186$ \\
\hline Ac- $24 \mathrm{~h}$ & $11.654 \pm 0.120$ & $17.045 \pm 0.194$ & 5.176 & 5.605 & 5.390 & $2.4106 \pm 0.504$ \\
\hline LD-0 $\min ^{\mathrm{b}}$ & $13.285 \pm 0.027$ & $|7.72| \pm 0.037$ & 4.374 & 4.497 & 4.436 & $4.6212 \pm 0.280$ \\
\hline LD-5 min & $13.458 \pm 0.174$ & $17.761 \pm 0.137$ & 4.328 & 4.277 & 4.303 & $5.0686 \pm 0.127$ \\
\hline LD-I5 min & $13.085 \pm 0.042$ & $17.292 \pm 0.223$ & 4.079 & 4.336 & 4.208 & $5.434 I \pm 0.68 I$ \\
\hline LD-30 min & $13.213 \pm 0.036$ & $18.355 \pm 0.015$ & 5.127 & 5.157 & 5.142 & $2.8318 \pm 0.042$ \\
\hline LD-I h & $13.233 \pm 0.013$ & $17.153 \pm 0.109$ & 3.833 & 4.006 & 3.919 & $6.62 \mathrm{I} 2 \pm 0.56 \mathrm{I}$ \\
\hline LD-3 h & $13.389 \pm 0.012$ & $|7.25| \pm 0.064$ & 3.825 & 3.899 & 3.862 & $6.8820 \pm 0.249$ \\
\hline LD-6 h & $12.497 \pm 0.007$ & $17.174 \pm 0.039$ & 4.655 & 4.699 & 4.677 & $3.9098 \pm 0.086$ \\
\hline LD-24 h & $12.172 \pm 0.084$ & $16.181 \pm 0.010$ & 3.943 & 4.076 & 4.010 & $6.2151 \pm 0.404$ \\
\hline HD-0 minc & $13.086 \pm 0.119$ & $|7.72| \pm 0.047$ & 4.473 & 4.797 & 4.636 & $4.0229 \pm 0.639$ \\
\hline HD-5 min & I I. $385 \pm 0.237$ & $15.483 \pm 0.127$ & 4.356 & 3.840 & 4.098 & $5.9338 \pm 1.483$ \\
\hline HD-I5 min & $12.164 \pm 0.086$ & $16.093 \pm 0.093$ & 3.802 & 4.056 & 3.929 & $6.5909 \pm 0.817$ \\
\hline HD-30 min & $12.098 \pm 0.099$ & $16.956 \pm 0.082$ & 4.730 & 4.987 & 4.858 & $3.46 \mathrm{II} \pm 0.434$ \\
\hline HD-I h & $|2.62| \pm 0.07 \mid$ & $16.749 \pm 0.012$ & 4.087 & 4.170 & 4.128 & $5.7196 \pm 0.234$ \\
\hline HD-3 h & $|2.120 \pm 0.09|$ & $16.809 \pm 0.023$ & 4.769 & 4.609 & 4.689 & $3.8822 \pm 0.306$ \\
\hline HD-6 h & $12.770 \pm 0.175$ & $|7.057 \pm 0.08|$ & 4.354 & 4.221 & 4.287 & $5.1275 \pm 0.334$ \\
\hline HD-24 h & $12.639 \pm 0.025$ & $|7.875 \pm 0.22|$ & 5.105 & 5.369 & 5.237 & $2.6631 \pm 0.343$ \\
\hline
\end{tabular}

Notes: acetone treatments in $5 \mathrm{~d}$ old female Ae. taeniorhynchus; ' bemethrin LD treatment in $5 \mathrm{~d}$ old female Ae. taeniorhynchus; ' pemethrin HD treatment in $5 \mathrm{~d}$ old female Ae. taeniorhynchus.

Abbreviations: Ac, acetone; h, hours; min, minutes; SD, standard deviation; LD, low dose; HD, high dose.

Table S5 Paired $t$-test data for comparison of relative AetNDUFS8 gene transcription between acetone, low dose (LD), and high dose (HD) permethrin treatments in Aedes taeniorhynchus

\begin{tabular}{|c|c|c|c|c|}
\hline Permethrin treatments & $\mathbf{N}$ & $d f$ & t-value & $P$-value \\
\hline LD and $A C 0$ min & 3 & 2 & -1.776 & 0.218 \\
\hline $\mathrm{LD}$ and $\mathrm{AC} 5 \mathrm{~min}$ & 3 & 2 & 8.200 & $0.015^{*}$ \\
\hline LD and $A C 15$ min & 3 & 2 & -13.405 & $0.006 *$ \\
\hline LD and $A C 30 \mathrm{~min}$ & 3 & 2 & I I.273 & $0.008^{*}$ \\
\hline $\mathrm{LD}$ and $\mathrm{AC} I \mathrm{~h}$ & 3 & 2 & -34.620 & $<0.00 I^{*}$ \\
\hline LD and $A C 3 \mathrm{~h}$ & 3 & 2 & -5.586 & $0.03 I^{*}$ \\
\hline LD and $A C 6 \mathrm{~h}$ & 3 & 2 & 10.039 & $0.010 *$ \\
\hline LD and AC $24 \mathrm{~h}$ & 3 & 2 & -94.119 & $<0.00 I^{*}$ \\
\hline $\mathrm{HD}$ and $\mathrm{AC} 0 \mathrm{~min}$ & 3 & 2 & -16.233 & $<0.004^{*}$ \\
\hline $\mathrm{HD}$ and $\mathrm{AC} 5 \mathrm{~min}$ & 3 & 2 & -0.666 & 0.574 \\
\hline $\mathrm{HD}$ and $\mathrm{AC} / 5 \mathrm{~min}$ & 3 & 2 & -15.466 & $0.004 *$ \\
\hline $\mathrm{HD}$ and $\mathrm{AC} 30 \mathrm{~min}$ & 3 & 2 & -11.273 & $0.008^{*}$ \\
\hline $\mathrm{HD}$ and $\mathrm{AC} I \mathrm{~h}$ & 3 & 2 & -88.490 & $<0.00 I^{*}$ \\
\hline $\mathrm{HD}$ and $\mathrm{AC} 3 \mathrm{~h}$ & 3 & 2 & 2.722 & 0.113 \\
\hline $\mathrm{HD}$ and $\mathrm{AC} 6 \mathrm{~h}$ & 3 & 2 & II.467 & $0.008^{*}$ \\
\hline $\mathrm{HD}$ and $\mathrm{AC} 24 \mathrm{~h}$ & 3 & 2 & -3.938 & 0.059 \\
\hline LD and HD 0 min & 3 & 2 & 3.943 & 0.059 \\
\hline LD and HD 5 min & 3 & 2 & -1.515 & 0.269 \\
\hline LD and HDI 5 min & 3 & 2 & -20.865 & $0.002 *$ \\
\hline LD and HD $30 \mathrm{~min}$ & 3 & 2 & 5.394 & $0.033^{*}$ \\
\hline LD and HD I h & 3 & 2 & 6.700 & $0.022^{*}$ \\
\hline LD and HD $3 \mathrm{~h}$ & 3 & 2 & 13.264 & $0.006 *$ \\
\hline LD and HD $6 \mathrm{~h}$ & 3 & 2 & -7.119 & $0.019 *$ \\
\hline LD and HD $24 \mathrm{~h}$ & 3 & 2 & $|4| .984$ & $<0.00 I^{*}$ \\
\hline
\end{tabular}

Note: *Statistical significance $(P<0.05)$.

Abbreviations: $A C$, acetone; $d f$, degrees of freedom, h, hours; min, minutes. 
Table S6 Expression of AetNADH5 in different developmental stages of Aedes taeniorhynchus

\begin{tabular}{|c|c|c|c|c|c|c|c|c|}
\hline \multirow[t]{2}{*}{ Sample stage } & \multirow{2}{*}{$\begin{array}{l}\text { Sample } \\
\text { name }\end{array}$} & \multirow{2}{*}{$\begin{array}{l}\text { Sample } \\
\text { time }\end{array}$} & \multicolumn{2}{|c|}{ Mean cycle threshold $(C t) \pm S D$} & \multicolumn{4}{|c|}{ Relative AetNADH5 expression level } \\
\hline & & & rR40s & AetNADH5 & $\Delta \mathbf{C t}-\mathbf{I}$ & $\Delta \mathrm{Ct}-2$ & $\Delta \mathrm{Ct}-3$ & $100 \times 2^{-\Delta C t} \pm S D$ \\
\hline \multirow[t]{2}{*}{ Eggs } & Egg I & I day & $|2.849 \pm 0.10|$ & $9.079 \pm 0.054$ & -3.925 & -3.615 & -3.769 & $|364.1 \pm| 46.9$ \\
\hline & Egg 2 & 3 day & $13.624 \pm 0.120$ & $9.065 \pm 0.041$ & -3.716 & -3.636 & -3.676 & $1278.1 \pm 35.84$ \\
\hline \multirow[t]{5}{*}{ Ist instar larvae } & Larvae I & $5 h^{a}$ & $10.512 \pm 0.447$ & $|0.05| \pm 0.15 \mid$ & -0.310 & -0.612 & -0.461 & $|37.66 \pm| 4.43$ \\
\hline & Larvae 2 & $21 h^{\mathrm{a}}$ & $10.676 \pm 0.333$ & $10.458 \pm 0.269$ & -0.154 & -0.282 & -0.218 & $116.28 \pm 5.156$ \\
\hline & Larvae 3 & $29 \mathrm{~h}^{\mathrm{a}}$ & II $.406 \pm 0.084$ & II.198 \pm 0.037 & -0.293 & -0.198 & -0.245 & $118.52 \pm 3.911$ \\
\hline & Larvae 4 & $44 \mathrm{~h}^{\mathrm{a}}$ & $9.1631 \pm 0.908$ & $8.8999 \pm 0.162$ & -0.101 & -0.425 & -0.263 & $120.01 \pm 13.53$ \\
\hline & Larvae 5 & $53 \mathrm{~h}^{\mathrm{a}}$ & $11.542 \pm 0.112$ & $9.3146 \pm 0.092$ & -2.048 & -2.027 & -2.228 & $468.37 \pm 6.672$ \\
\hline \multirow[t]{2}{*}{ 2nd instar larvae } & Larvae 6 & $69 \mathrm{~h}^{\mathrm{a}}$ & II. $375 \pm 0.098$ & $9.3639 \pm 0.074$ & -1.988 & -2.035 & -2.011 & $403.18 \pm 6.582$ \\
\hline & Larvae 7 & $77 \mathrm{~h}^{\mathrm{a}}$ & II. $.769 \pm 0.029$ & $9.143 \pm 0.003$ & -2.660 & -2.591 & -2.626 & $617.16 \pm 14.74$ \\
\hline \multirow[t]{2}{*}{ 3rd instar larvae } & Larvae 8 & $93 \mathrm{~h}^{\mathrm{a}}$ & $10.874 \pm 0.057$ & $7.909 \pm 0.099$ & -3.006 & -2.924 & -2.965 & $780.74 \pm 22.32$ \\
\hline & Larvae 9 & $101 h^{a}$ & $10.719 \pm 0.388$ & $7.929 \pm 0.065$ & -2.856 & -2.724 & -2.789 & $691.51 \pm 31.63$ \\
\hline \multirow[t]{4}{*}{ 4th instar larvae } & Larvae 10 & $117 h^{\mathrm{a}}$ & $10.245 \pm 0.259$ & $7.675 \pm 0.118$ & $-2.45 \mathrm{I}$ & -2.687 & -2.569 & $593.58 \pm 48.66$ \\
\hline & Larvae II & $125 h^{\mathrm{a}}$ & 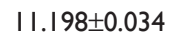 & $8.122 \pm 0.027$ & -3.045 & -3.101 & -3.076 & $843.54 \pm 18.27$ \\
\hline & Larvae 12 & $|4| h^{\mathrm{a}}$ & $12.446 \pm 0.069$ & $10.019 \pm 0.018$ & -2.514 & -2.339 & -2.427 & $537.61 \pm 32.46$ \\
\hline & Larvae 13 & $149 h^{\mathrm{a}}$ & $12.835 \pm 0.092$ & $11.022 \pm 0.008$ & -1.913 & -1.712 & -1.813 & $351.25 \pm 24.49$ \\
\hline \multirow[t]{2}{*}{ Pupae } & $\mathrm{PI}$ & $165 h^{a}$ & $13.134 \pm 0.003$ & I I.055 \pm 0.069 & -2.011 & -2.146 & -2.078 & $422.33 \pm 19.69$ \\
\hline & P3 & $173 h^{a}$ & $13.962 \pm 0.124$ & $9.167 \pm 0.012$ & -4.658 & -4.931 & -4.795 & $2775.9 \pm 236.1$ \\
\hline \multirow[t]{6}{*}{ Adults } & $\mathrm{Al}(\mathrm{M})^{\mathrm{b}}$ & I day & $12.939 \pm 0.073$ & $8.079 \pm 0.197$ & -5.056 & -4.661 & -4.859 & $2903.4 \pm 398.4$ \\
\hline & $\mathrm{A} 2(\mathrm{M})^{\mathrm{b}}$ & 5 day & $16.684 \pm 0.019$ & $12.056 \pm 0.013$ & -4.634 & -4.622 & -4.628 & $2472.7 \pm|0.7|$ \\
\hline & $\mathrm{A} 3(\mathrm{M})^{\mathrm{b}}$ & 10 day & $15.954 \pm 0.045$ & $13.012 \pm 0.196$ & -3.138 & -2.746 & -2.942 & $768.64 \pm 104.9$ \\
\hline & $A I(F)^{c}$ & I day & $13.845 \pm 0.027$ & $9.221 \pm 0.359$ & -4.958 & -4.292 & -4.625 & $2467.0 \pm 575.6$ \\
\hline & $\mathrm{Al}(\mathrm{F})^{\mathrm{c}}$ & 5 day & $14.752 \pm 0.538$ & II. $.45 \pm 0.083$ & -3.690 & -2.985 & -3.607 & $1218.4 \pm 269.8$ \\
\hline & $A 2(F)^{c}$ & 10 day & $13.838 \pm 0.006$ & $11.252 \pm 0.095$ & -2.674 & -2.497 & -2.587 & $600.26 \pm 37.06$ \\
\hline
\end{tabular}

Notes: ahours post hatch; 'bmales; 'females.

Abbreviations: $h$, hours; $F$, female; $M$, male; SD, standard deviation.

Table $\mathbf{S 7}$ Paired $t$-test data for comparison of relative AetNADH5 gene transcription between female $(F)$ and male $(M)$, as well as different ages between the same sex (either female or male) in Aedes taeniorhynchus

\begin{tabular}{lllll}
\hline Sexes and ages & $\mathbf{N}$ & df & t-value & P-value \\
\hline FI-d and MI-d & 3 & 2 & -3.989 & 0.057 \\
F5-d and M5-d & 3 & 2 & -8.497 & $<0.014^{*}$ \\
FI0-d and MI0-d & 3 & 2 & -4.399 & $0.048^{*}$ \\
FI-d and F5-d & 3 & 2 & 6.908 & $0.020^{*}$ \\
FI-d and FI0-d & 3 & 2 & 6.142 & $0.025^{*}$ \\
MI-d and M5-d & 3 & 2 & 1.999 & 0.184 \\
MI-d and MI0-d & 3 & 2 & 12.669 & $0.006^{*}$ \\
\hline
\end{tabular}

Note: *Statistical significance $(P<0.05)$.

Abbreviations: $d$, days; $d f$, degrees of freedom.
Table S8 Paired $t$-test data for comparison of relative AetNADH5 gene transcription between eggs, larvae, pupae, and adults in Aedes taeniorhynchus

\begin{tabular}{|c|c|c|c|c|}
\hline Stage and ages & $\mathbf{N}$ & $d f$ & t-value & $P$-value \\
\hline Egg I and egg 3 & 3 & 2 & -1.175 & 0.361 \\
\hline Egg 3 and larvae I & 3 & 2 & 39.295 & $<0.00 I^{*}$ \\
\hline Larvae I and larvae 2 & 3 & 2 & 3.276 & $<0.022^{*}$ \\
\hline Larvae 2 and larvae 3 & 3 & 2 & 6.000 & 0.438 \\
\hline Larvae 3 and larvae 4 & 3 & 2 & -2.242 & 0.075 \\
\hline Larvae 4 and larvae 5 & 3 & 2 & 12.000 & 0.844 \\
\hline Larvae 5 and larvae 6 & 3 & 2 & -2.242 & $0.031^{*}$ \\
\hline Larvae 6 and larvae 7 & 3 & 2 & -28.819 & $0.00 I^{*}$ \\
\hline Larvae 7 and larvae 8 & 3 & 2 & 14.259 & $0.005^{*}$ \\
\hline Larvae 8 and larvae 9 & 3 & 2 & 5.385 & $0.033^{*}$ \\
\hline Larvae 9 and larvae 10 & 3 & 2 & 2.394 & 0.139 \\
\hline Larvae I0 and larvae II & 3 & 2 & -14.178 & $0.005^{*}$ \\
\hline Larvae II and larvae I2 & 3 & 2 & 10.427 & $0.009 *$ \\
\hline Larvae 12 and larvae 13 & 3 & 2 & 40.517 & $<0.00 I^{*}$ \\
\hline Larvae I 3 and pupae I & 3 & 2 & -2.776 & 0.109 \\
\hline Pupae I and pupae 2 & 3 & 2 & -28.885 & $0.001 *$ \\
\hline Pupae 2 and MI-d & 3 & 2 & -0.526 & 0.652 \\
\hline Pupae 2 and FI-d & 3 & 2 & 0.933 & 0.449 \\
\hline
\end{tabular}

Note: *Statistical significance $(P<0.05)$.

Abbreviations: $d$, day; $d f$, degrees of freedom. 
Open Access Insect Physiology

Dovepress

\section{Publish your work in this journal}

Open Access Insect Physiology is an international, peer-reviewed, open access journal publishing original research, reports, reviews

Visit http://www.dovepress.com/testimonials.php to read real quotes and commentaries on all areas of insect physiology. The manuscript management system is completely online and includes a very quick and fair peer-review system, which is all easy to use.

from published authors.

Submit your manuscript here: http://www.dovepress.com/open-access-insect-physiology-journal 